\title{
Imagining and Implementing Healthy City Interventions: Combined Results from Parallel Concept Mapping Exercises in Montreal with Community Members and Stakeholders
}

\section{Zoe Poirier Stephens}

Université de Montréal École de Santé Publique: Universite de Montreal Ecole de Sante Publique https://orcid.org/0000-0002-3918-1414

\section{Caislin Leah Firth}

University of Washington

Michael Cantinotti

Université du Québec à Trois-Rivières: Universite du Quebec a Trois-Rivieres

\section{Daniel Fuller}

Memorial University of Newfoundland

\section{Meghan Winters}

Simon Fraser University

Yan Kestens ( $\square$ yan.kestens@umontreal.ca)

Université de Montréal https://orcid.org/0000-0003-2619-5750

\section{Research}

Keywords: Implementation, concept mapping, built environment, healthy cities, urban planning, decisionmaking, sustainability

Posted Date: September 28th, 2021

DOl: https://doi.org/10.21203/rs.3.rs-889586/v1

License: (c) (i) This work is licensed under a Creative Commons Attribution 4.0 International License. Read Full License 


\section{Abstract}

Background Built environment interventions provide structural solutions to complex urban challenges. Though community voices are part of municipal decision-making, planners and public health professionals need tools to better integrate their perspectives for desired changes (what) in the successful implementation of built environment programs and interventions (how).

Methods Two simultaneous concept mapping exercises were conducted as part of the INTErventions, Research, and Action in Cities Team (INTERACT) study. Community members (a subsample of the INTERACT cohort) were prompted about neighbourhood changes that could improve their quality of life, while stakeholders (city staff, NGO, public health officials) were prompted about factors that contribute to successful implementation of urban interventions. Through each exercise, items were generated, grouped, and rated on importance and feasibility. Concept maps were produced using multi-dimensional scaling and hierarchical cluster analysis. The clusters or themes identified by community members' and the stakeholders' were combined into a Community $x$ Stakeholder Matrix, which served to frame a discussion with stakeholders on built environment interventions.

Results Thirty-two community members generated 41 unique responses, which resulted in 6 clusters: 1: Strengthen public transportation, 2: Reduce space dedicated to cars, 3: Foster local social connections, 4: Develop quality cycling infrastructure, 5: Improve pedestrian accessibility, and 6: Green the city. Thirtyseven stakeholders generated 40 unique items, which resulted in 5 clusters: 1 : Collaboration with stakeholders and citizens, 2: Planning and evaluation, 3: Common vision for the future, 4: Regulatory framework and funding, and 5: Context-informed approach. The clusters were then used to produce a Community $x$ Stakeholder Matrix to inform healthy cities intervention planning and evaluation.

Conclusion Capturing the collective vision of our urban environments and understanding the processes underlying change through concept mapping can lead to more inclusive and successful changes. We propose combining different perspectives in a matrix as a method for evaluation and strategic planning that can help facilitate the integration of community voices into operational planning.

\section{Contributions To The Literature}

- Mixed methods approaches like concept mapping have been used to gather community and stakeholder perspectives, yet have rarely been combined to consider the way different community desires (what) are implemented (how).

- This research proposes a tool for planners and public health professionals to integrate community perspectives when implementing built environment programs/interventions.

- Implementing successful built environment interventions requires facilitators that relate to these five themes: Collaboration with stakeholders and community members, 2: Planning and evaluation, 3 : Common vision for the future, 4: Regulatory framework and funding, and 5: Context-informed approach. These themes should be considered through the lens of community aspirations. 


\section{Background}

Cities are partly shaped by community desires and aspirations, partly by the capacity of cities to implement urban changes. Built environment interventions provide structural solutions to complex urban challenges. They may take the form of greening programs, transportation infrastructure, or traffic calming measures. They are generally linked to strategic plans aiming to tackle 'wicked problems' - problems that are difficult or impossible to solve such as climate change, homelessness, or social injustice (1), through promotion of sustainable development, resilience, mitigation of climate change, or reduction in structural inequities in access to amenities and opportunities. The implementation - "process of putting to use or integrating evidence-based interventions within a setting" (2) - of built environment interventions, such as active transportation infrastructure or greening policies unfolds largely within the sphere of urban planning, involving its actors and processes. Yet, these interventions can have substantial co-benefits beyond the stated aims, contributing to population health $(3,4)$. Tools are needed for public health professionals and urban planners to integrate community perspectives when implementing built environment interventions.

The inclusion of community perspectives is critical to the process of implementing built environment interventions, yet this requires careful consideration of timing, scope, and scale of participation to be done well. Frustrations arise from community members when they are consulted on a project for which the outcome is already decided (5). Other important aspects of public participation are scope and scale of consultation, where there may be a mismatch between what decision-makers can hear, and what community members want to say. For example, municipal planners 'tend to expect broader vision statements and general directions to arise from consultation while community members expect more specific action-orientated results' (Shipley 2012, p. 23). Community-engaged planning relies on getting community input from the start, which disrupts traditional top-down planning practices. Despite efforts to better integrate perspectives from the public, municipal planners may not have the structure or capacity to meaningfully do so $(6,7)$.

Research on factors that lead to the successful implementation of built environment interventions have pointed to the importance of multisectoral and multilevel stakeholder collaborations, effective communication with the public, and adequate funding $(8,9)$. Stakeholders play different roles, with a range of powers, priorities, and responsibilities, which shape each's view on implementation of built environment changes. Engaging residents on ways to improve the built environment is key, since they are end-point users of implementation (10). Considering this range of views, tools are needed to synthesize common visions around these issues, while integrating a variety of perspectives, from ideation to implementation (11). Capturing potentially different perspectives - community members' understanding of local realities, and stakeholders' knowledge of processes - may provide the needed matrix of factors needed to facilitate future planning.

Mixed methods approaches like concept mapping have been used to gather perspectives from community members, and from other stakeholders responsible for the implementation process (12-14). 
Involving phases including ideation, sorting and rating, and visualisation and interpretation of concept maps, the method can easily be conducted online, increasing potential reach. It is a participatory mixed method that allows to synthesise a shared vision around what can be a complex, multi-factorial issue, while providing a visual representation of the underlying structure of people's understanding of that issue (15). Concept mapping has been used in a variety of urban planning $(9,16,17)$ or health research contexts $(13,18-20)$. Because of its anonymous approach where every participant's voice holds equal weight, online concept mapping offers an interesting and underused potential both for public consultation regarding neighbourhood change (21), and to reveal stakeholders' perspectives on factors underlying the successful implementation of built environment interventions.

Our aim was to develop a strategic planning matrix that integrates community perspectives on 'what' built environment interventions would improve quality of life and sustainability on one hand, and stakeholder perspectives on 'how' successful built environment change interventions should be implemented on the other hand. We use two concept mapping exercises conducted among community members and stakeholders to identify the matrix's main themes. Combining their respective emerging themes, the matrix offers a synthetic frame to consider both community wants and practical considerations for successful implementation. It can serve as a tool for evaluation and strategic planning and helps facilitate the integration of community voices into operational planning.

\section{Methods}

Study context This research was conducted as part of the INTErventions, Research, and Action in Cities Team (INTERACT), a research collaboration of scientists, urban planners, and engaged community members uncovering how the design of our cities is shaping the health and well-being of Canadians (22). In Montreal, INTERACT assesses built environment interventions that are related to the Plan Montréal durable 2016-2020, a metropolitan-wide sustainability plan. Grounded in this sustainability focus, although not specific to this Plan Montreal durable, this concept mapping exercise assessed both community members' perspectives on desired interventions, and stakeholders' perspectives on success factors of an intervention. While community members are key stakeholders in any urban change project, we sought to study their specific perspectives as local experts on desired changes; they therefore form a separate group from the stakeholder group.

Recruitment The community member group was assembled by inviting a random subsample of 100 participants from the INTERACT cohort (25 Anglophones and 75 Francophones, corresponding to the linguistic breakdown in Montreal) to participate. Participants had to live on the Island of Montreal, or in Laval, Longueuil, Brossard and Saint-Lambert. In parallel, we invited 150 stakeholders, identified through the INTERACT Advisory Committee. This committee comprises professionals from the City of Montreal, the Montreal public health department (Direction régionale de la santé publique), and NGOs that advocate for issues surrounding health promotion, physical activity policy, inclusion, active transportation, and urban planning. Stakeholders were also encouraged to share the invitation to join the study within their 
organization and broader professional network. All participants had to be aged 18 years and older. Ethics approval was received by the Comité d'éthique de recherche at CHUM (2017-7024, CE 16.397 - ID).

Overview of the concept mapping process: The concept mapping process has three phases: 1 . Statement generation and subsequent reduction, 2. Statement sorting and rating, analysis and generation of maps, and 3. Concept map interpretation and naming of clusters. (23). Phase 3 is often done with participants but can also be done by a research team. For this exercise, the research team proposed the cluster names, and validated and refined these with the Advisory Committee during an interpretation workshop.

Data Collection and Analysis: PHASE 1 Statement generation - November 2018 We provided stakeholders and community members links to separate web-based concept mapping exercise (Insight Forming, Polygon Research Inc.). The exercise was administered in both English and French for the community member group, and in French only for the stakeholder group (as the mandatory working language in Quebec). Participants in the community group were asked to respond to the following prompt: In your opinion, what interventions should be put in place in your neighbourhood to improve your quality of life and that of your fellow citizens? [French : Selon vous, quelles interventions devraient être mises en place dans votre quartier pour améliorer votre qualité de vie et celle de vos concitoyens?] Demographic information on participants was drawn from INTERACT cohort data collection, launched the same year (June 2018). Participants in the stakeholder group were asked to provide information on their role, duration in that role, type of organization, and whether they were partners on the Plan Montréal durable. Stakeholders then responded to the following prompt: In order to improve the quality of life of citizens and contribute to the sustainable development of cities, we must intervene on the built environment. Based on your experience, what are the factors that contribute to successful interventions? [French : En vue d'améliorer la qualité de vie des citoyens et de contribuer au développement durable des villes, il faut intervenir sur le cadre bâti. En vous basant sur votre expérience, quels sont les facteurs qui contribuent à des interventions réussies?]

Once the brainstorming phase was complete, the research team reviewed the statements generated by stakeholders. Duplicate or similar statements were removed, multiple concepts within one statement were separated, and the statements were edited for clarity (spelling, grammar). The number of items was reduced to roughly 40 ahead of Phase 2 , to ease participation for the next steps. For the community group, the bilingual research team translated items generated in Phase 1 to ensure the full set of ideas was ranked and rated in Phase 2 by both Francophone and Anglophone participants.

PHASE 2 Statement sorting and ranking-December 2018-March 2019: In this next phase, we asked both the community group and stakeholder group to use the online application to: 1) Sort the list of statements into conceptually similar piles and give the piles a short title; and 2) Rate each statement using a Likert scale from one to four along two criteria: importance and feasibility ( $1=$ not important / not feasible at all to $4=$ very important $/$ very feasible). Multiple reminders were sent and the participation period was extended to allow for higher participation. 
Each participant's sorting of items provides a square proximity matrix identifying which statements were sorted together. The sum of these individual matrices provides the co-occurrence between concepts based on the group of participants. The concept mapping approach uses these data to produce concept maps through cluster analysis and multidimensional scaling. A Ward cluster analysis was run to identify groups of concepts that belong together, using the 'cluster' (version 2.0.3) (24) and 'NbClust' (version 3.0) R packages (25). Multidimensional scaling using the R-package 'vegan' (version 2.3-1) (26) projects the proximity matrix on a two-dimension map, and visualize the relative position of the statements and clusters. Silhouette scores, a measure that indicates the similarity of a statement to the cluster it is assigned to (cohesion) relative to other clusters (separation), were used to examine the number and relevance of potential clustering solutions (27). To optimise cluster solutions, items with negative silhouette coefficients indicating they may have been sorted quite differently or simply left unsorted by participants were removed. The quality of the dimensional projection was evaluated using the Kruskal Stress Index knowing that a stress value of 0.20 or lower is considered desirable (28). The analysis procedures were conducted separately for each group.

PHASE 3. Map Interpretation and Matrix Creation October 2019 - To interpret the resulting concept maps, the research team gathered the Advisory Committee (of which some members had participated in Phases 1 and 2) to review the proposed names of the clusters. Then, the main clusters or themes emerging from community members' vision about desired neighbourhood interventions (the what?) were combined with stakeholders' understanding of factors contributing to successful implementation (the how?) in a matrix. This Community $x$ Stakeholder Matrix was then used as a tool during an interpretation workshop held at the Université de Montréal Hospital Research Center on October 2nd, 2019, to frame an evaluative discussion on sustainability programs and policies with the Advisory Committee.

\section{Results}

\section{Participants' characteristics}

The community member sample comprised 14 men and 18 women, most born in Canada $(n=24)$, and had at least one university degree $(n=25)$ (Table 1$)$. The vast majority identified as white. Participants' household incomes were generally well distributed: a quarter of participants had a household income of less than $50 \mathrm{k}$, and close to a third more than $100 \mathrm{k}$ annually. With a mean age of 50 years-old, most participants were employed full time $(n=18)$ and close to a third of participants were retired $(n=12)$. Most participants lived in the central neighbourhoods of Montreal. Community member participants tended to be less racially diverse, better educated, and older than the Montreal area population. 
Table 1

Composition of community group who shared perspectives on interventions needed for neighbourhood quality of life

\begin{tabular}{|c|c|}
\hline Community Group & $N=32$ \\
\hline \multicolumn{2}{|l|}{ Gender } \\
\hline Man & 14 \\
\hline Woman & 18 \\
\hline \multicolumn{2}{|l|}{ Ethnicity } \\
\hline White & 29 \\
\hline Latin American & 1 \\
\hline Arab & 1 \\
\hline Southeast Asian & 1 \\
\hline \multicolumn{2}{|l|}{ Education } \\
\hline Less than a university degree & 7 \\
\hline University degree & 25 \\
\hline \multicolumn{2}{|l|}{ Household annual income } \\
\hline$<\$ 50,000$ & 8 \\
\hline$\$ 50,000-\$ 99,999$ & 13 \\
\hline$\$ 100,000+$ & 10 \\
\hline \multicolumn{2}{|l|}{ Employment } \\
\hline Employed or self-employed full-time & 18 \\
\hline Employed or self-employed part-time & 1 \\
\hline Retired & 12 \\
\hline Student full-time & 1 \\
\hline \multicolumn{2}{|l|}{ Age } \\
\hline $18-24$ & 1 \\
\hline $25-44$ & 12 \\
\hline $45-64$ & 11 \\
\hline $65+$ & 8 \\
\hline
\end{tabular}


Among the 37 participants who joined the stakeholder concept mapping exercise (Table 2), most conducted their work on the Island of Montreal $(n=33)$ and several were directly involved in the implementation of the Plan Montréal durable $(n=17)$. More than half worked for non-governmental organizations $(n=21)$, and most had been in their position for 5 years or less $(n=33)$.

Table 2

Composition of stakeholder group sample who shared factors contributing to successful built environment interventions

\begin{tabular}{|l|l|}
\hline Stakeholder Group & $\mathbf{N}=\mathbf{3 7}$ \\
\hline Time in current role & \\
\hline 0 to 2 years & 23 \\
\hline 3 to 5 years & 10 \\
\hline 6 to 10 years & 2 \\
\hline More than 10 years & 2 \\
\hline Stakeholder organization & \\
\hline Non-profit organizations & 21 \\
\hline Institutions & 8 \\
\hline Municipal administration & 7 \\
\hline Public & 1 \\
\hline Organization is involved in the Montreal Sustainability plan & 17 \\
\hline Stakeholder conducts work on Island of Montreal & 33 \\
\hline
\end{tabular}

\section{Concept maps}

At Phase 1, the community group generated 59 items, which the research team reduced to 40 by removing redundant or too general ideas (i.e. more schools). The stakeholder group generated 72 items, which the research team reduced to 41 items by combining repeating answers. 
Table 3

Participation rates and items generated in the parallel concept mapping exercises

\begin{tabular}{|c|c|c|}
\hline Platforms & Community members & Stakeholders \\
\hline $\begin{array}{l}\text { Problem } \\
\text { statement }\end{array}$ & $\begin{array}{l}\text { In your opinion, what interventions should be put } \\
\text { in place in your neighbourhood to improve your } \\
\text { quality of life and that of your fellow citizens? }\end{array}$ & $\begin{array}{l}\text { Based on your experience, } \\
\text { what are the factors that } \\
\text { contribute to successful } \\
\text { interventions? }\end{array}$ \\
\hline $\begin{array}{l}\text { Number of } \\
\text { stakeholders } \\
\text { invited }\end{array}$ & 100 & 150 \\
\hline $\begin{array}{l}\text { Number of } \\
\text { participants }\end{array}$ & 32 & 37 \\
\hline $\begin{array}{l}\text { Participation } \\
\%\end{array}$ & $32 \%$ & $24.6 \%$ \\
\hline \multicolumn{3}{|c|}{ Phase 1: Statement generation } \\
\hline $\begin{array}{l}\text { Number of } \\
\text { participants }\end{array}$ & 22 & 25 \\
\hline $\begin{array}{l}\text { Number of } \\
\text { statements } \\
\text { generated }\end{array}$ & 59 & 72 \\
\hline $\begin{array}{l}\text { Number of } \\
\text { statements } \\
\text { retained for } \\
\text { Phase } 2\end{array}$ & 40 & 41 \\
\hline \multicolumn{3}{|c|}{ Phase 2: Statement sorting and ranking } \\
\hline $\begin{array}{l}\text { Number of } \\
\text { participants }\end{array}$ & 23 & 16 \\
\hline \multicolumn{3}{|l|}{$\begin{array}{l}\text { Phase 3: } \\
\text { Interpretation }\end{array}$} \\
\hline $\begin{array}{l}\text { Number of } \\
\text { participants }\end{array}$ & $\mathrm{n} / \mathrm{a}$ & 20 \\
\hline
\end{tabular}

\section{Community group results}

The cluster analysis of the 40 items to the prompt, "In your opinion, what interventions should be put in place in your neighbourhood to improve your quality of life and that of your fellow citizens?" led to a 6cluster solution, with a silhouette index of 0.57 , indicating a reasonable structure (29). Item 4 , "Reduce the overall size of streets to promote usable public areas" was excluded because of a negative silhouette score, thus the solution with a stress index of 0.06 , indicative of a good fit. The research team provided initial names to the clusters, and these were refined with the Advisory Committee. Figure 1 shows the community group concept map with six clusters, 1: Strengthen public transportation, 2: Reduce space dedicated to cars, 3: Foster local social connections, 4: Develop quality cycling infrastructure, 5: Improve 
pedestrian accessibility, and 6: Green the city. We discuss items within each of these clusters below, highlighting those that were rated very feasible, or very important.

The community members' concept map reveals several themes around mobility and transportation as neighbourhood interventions that would improve their neighbours' quality of life. Transportation infrastructure, like cycling networks, transit stations and routes and pedestrian areas represent core elements of one's neighbourhood, and features in community members' views on how to improve quality of life in a neighbourhood. The items within cluster 5 , improving pedestrian accessibility are close to both the transport mode clusters to the left, and the two clusters to the right, which relate to local social connections and greening initiatives, indicating that cognitively, actions to improve pedestrian accessibility relate to both hard infrastructure changes and to soft infrastructure changes to streetscapes and neighbourhood environment.

Ratings for importance revealed items relating to transit were seen as most important. Item 35, "Improve transit services" was ranked the most important (3.6 on a scale of $1-4)$, followed by item 15 , "Provide cheaper and better connected public transit" (3.4). The least important (2.0) was 13, "Respect the tranquility of parks by reducing noisy activities (e.g. night festival events, 'revitalization' program)". Items varied in specificity; for example, the relatively specific item 34, "making better east-west bus connections" had both an average importance and feasibility score, while broader statements, like improving transit services (item 35) had similar average feasibility scores, but much higher importance scores. An additional table shows individual scores for each item by cluster (see Table A1: Community group items by cluster).

\section{Stakeholder group results}

The cluster analysis of the 41 items to the prompt led to a 5-cluster solution, with a silhouette index of 0.34 , indicating a weak structure. Items $13,17,21,30$ and 3 were removed for the multidimensional scaling, leaving 36 items. The stress index was 0.147 , indicative of a poor to fair fit. Interpretation of the 5 clusters led to naming the clusters as 1: Collaboration with stakeholders and citizens, 2: Planning and evaluation, 3: Common vision for the future, 4: Regulatory framework and funding, and 5: Contextinformed approach.

The item seen as most important was item 11, "Coordinate land use planning and transport planning", while the most feasible was item 41, "Make a preliminary analysis of the area and its socioeconomic dynamics". The importance of items within clusters was generally balanced, the average importance rating for each cluster varied between 3.2 and 3.3. The least feasible item related to funding, item 23, "Securing massive investments". An additional table shows individual scores for each item by cluster (see Table A2: Stakeholder group items by cluster).

\section{Community x Stakeholder Matrix}

INTERACT's Advisory Committee came together to interpret the results of the two maps and item rankings. As stakeholders, they were asked to interpret both their own responses, as well as those 
provided by the community group. The clusters obtained from the two concept maps were then combined into a matrix, where rows listed the community members' clusters, and columns the stakeholder's clusters. Doing so, each desired cluster or theme expressed by community members could be considered in light of a stakeholder cluster (e.g. How can public transportation be strengthened through collaboration with stakeholders and community members?). The resulting matrix (Fig. 3) offers a synthetic frame to consider both community wants and practical considerations for successful implementation. Each cell can be used to evaluate existing or lacking processes or programs addressing both dimensions. For example, when considering the fostering of local connections (cluster 3 , community group), what procedures or programs do currently address the need for collaboration between stakeholders and community members (cluster 1 , stakeholders)?

To interpret the results using the Community $x$ Stakeholder Matrix, stakeholders were divided into groups to discuss additions or improvements to existing programs regarding one community cluster or row of the matrix. One breakout group looked at how stakeholders could strengthen public transportation (community cluster 1 ) through the lens of the five stakeholder clusters and discussed prospective or existing programs. The ideas raised during these sessions included hosting discussions with the public on transportation ahead of major changes (stakeholder cluster 1), tapping into 'real' data, or user data on transit times and trips (stakeholder cluster 2), showcasing examples or success stories of transit upgrade impacts (stakeholder cluster 3), collecting data on motivation for using transit and the perceived benefits of transit (stakeholder cluster 4), and better integrating data into decision-making (stakeholder cluster 5). Another group looking at fostering social connectedness (community cluster 3 ) mentioned existing programs which could be expanded or scaled out, such as comité de ruelles vertes (committees of residents who plan and maintain a green alleyway). Through this exercise it was noted that the matrix was a tool to allow stakeholders to not only review existing programs and procedures, but also to imagine possible innovations, accounting for both community wants and stakeholders' success factors.

\section{Discussion}

The purpose of this paper was to develop a tool that integrates the community and stakeholder perspectives to indicate 'what' built environment interventions related to quality of life and sustainability were desired and 'how' they needed to be implemented to be successful. Through two parallel concept mapping exercises, we created the Community $x$ Stakeholder Matrix that combines community members' vision for a better neighbourhood with more operational considerations faced by implementing stakeholders. The matrix can serve to anchor strategic planning of healthy cities.

Community responses about neighbourhood interventions that would improve quality of life covered a broad range of domains, from waste management, to political dynamics, to transportation, and to urban agriculture. Their perspectives illustrate the multiplicity of factors involved in the complex system of cities and people-centered urban planning. Some items were specific built environment interventions (e.g. 'Install more traffic calming measures on residential streets'), while others related to policy or programming (e.g. 'Allow more mixed zoning regulations to permit smaller and more affordable 
housing'). Tension among different visions for what contributes to neighbourhood quality of life are apparent in some items (e.g. 'Prioritize sidewalks and streets during snow removal and not bike lanes'). As mediators between different visions for sustainability and livability (30), cities must contend openly with these tensions.

Community members tended to suggest actions that were tangible and relate to how they might impact the neighbourhood or its user (e.g. "Improve the design of streets, sidewalks and commercial space to facilitate access for people with disabilities"). In contrast, policy documents such as Montreal's sustainability plan can list actions that lack meaning for the end-user of the investments; Plan Montréal durable for example commits to "doubling the annual budget dedicated to universal accessibility" instead of identifying specific interventions to be funded through this budget. This points to the disconnect between community member visions and the way they are translated into "policy-speak" by stakeholders, something the City has recognized in its own evaluation of the Plan Montréal durable (31).

Stakeholders provided broad orientations on factors contributing to successful interventions and the relatively weak structure of the stakeholder map suggests that there is no strong consensus from stakeholders on how these factors relate to one another. This may be due to the varying roles and experiences in urban intervention implementation of the respondents (10). Participants came from NGOs, municipal administrations, and public health authorities. With a larger number of participants, it would be possible to produce not only the overall consensus map, but also group-specific maps, to assess how much visions diverge between sub-groups (12).

While concept mapping is generally used to answer one prompt, we combined the resulting emerging themes to link the what and the how. This resulted in a synthetic matrix in which city planners can consider at once community aspirations and the reality of operations, while community members can better understand the processes required to turn their aspirations into action. In our facilitated discussion, INTERACT's Advisory Committee used the matrix to center community members' perspectives in their discussion of the processes and programs in place around sustainable development. The conversation around strengthening transit brought to the fore pieces of the implementation puzzle that focused on community member perspectives, like including their experiences and data into the process. Beyond interpretation by stakeholders, the matrix may also inform the ways in which stakeholders communicate to the public, as it highlights the public's vocabulary and perspectives on a given topic.

A matrix such as this can serve as a method for evaluation and strategic planning and can help facilitate the integration of community voices into operational planning. Developing participatory local governance requires 'working on both sides of the equation' (7). On one end, community members must feel empowered to participate in decision-making; on the other, decision-makers have to learn to be responsive to community participation, and ready to hear and incorporate that feedback. In their concept mapping exercise, community members tended to identify concrete actions over broad policy orientations. For municipal decision makers to be more responsive to community voices, attention is needed to better translate community actions into policy orientations, and then demonstrate how community members' 
input shaped the implementation of that policy. Concept mapping and the resulting matrix can serve as a tool to develop this capacity. The proposed matrix of dual concept mapping exercises could be used in a variety of contexts. It is particularly adapted when two groups play different roles or may have distinct interests for a common, relatively complex, issue. It could for example apply to doctor - patient experiences in improving health services delivery, where patients may express their needs to better access services, and health professionals on how they perceive the potential for organizational change (32)

As cities look for new solutions to sustain the future of our planet and population health and equity, community members need to be on board. While aspirations and understanding of how communities should be transformed can vary, a certain united vision is useful to move forward. The exercise of visioning a better future fulfills an important function in planning and decision-making, producing a reference point for developing strategies to transition from the current state to a desirable future state (33). Yet, broad policy orientations can seem vague and opaque to the general public, while on-the-ground changes to the built environment are tangible signs of policy action. Success in implementing these changes (i.e. high quality design, timeliness and duration, attention to equity impacts, resident satisfaction, etc.) can have a greater effect beyond the project, by building trust towards and responsiveness from decision-makers. More broadly, such a Community x Stakeholder Matrix can help link complementary visions and needs, and reinforce trust from the public through a transparent and participative process.

\section{Limitations}

Results from the concept mapping exercises are of course context specific. Concept mapping offers a snapshot of the views of the participants, and therefore, findings may not be generalizable to different groups or contexts, though, the proposed approach is easily reproducible. One of the challenges that remains concerns participation: while we had co-developed the exercise and the research questions with our advisory board, and partly used their networks for recruitment, the response rate from stakeholders was relatively low. Due to relatively low sample sizes, it was not possible to conduct stratified analyses, for example, for different types of stakeholders.

\section{Conclusion}

Community driven built environment interventions have the potential to make our cities healthier. To better integrate community and stakeholder perspectives, we developed the Community $x$ Stakeholder Matrix using parallel concept mapping exercises. One concept mapping revealed themes relating to community's desire for neighbourhood change ('what'), the other stakeholders' understanding of factors that contributed to successful implementation of interventions ('how'). We combined these themes to make the Community $x$ Stakeholder Matrix, which served as a tool for evaluation and strategic planning and facilitated the integration of community voices into operational planning. Concept mapping can integrate the diverse perspectives of stakeholders and community members, so as to illustrate a collective vision of a better city, and to refine implementation of built environment changes. Results can 
be used at multiple scales for consultation and decision making, and the exercise can be repeated through time to analyze changing visions, as new realities and challenges arise. Capturing the collective vision of our urban environments and understanding the processes underlying change can help shape a more just and participative healthy cities.

\section{Abbreviations}

INTERACT INTErventions, Research, and Action in Cities Team

NGO Non-governmental organizations

\section{Declarations}

\section{Ethics approval and consent to participate}

Ethics approval was received by the Comité d'éthique de recherche at CHUM (2017-7024, CE 16.397 - ID). All participants have given informed consent to participate in the INTERACT study for the purpose of the research detailed in this manuscript.

\section{Consent for publication}

Not applicable

\section{Availability of data and materials}

The datasets generated and/or analyzed during the current study are not publicly available because they contain sensitive data about participants but are available from the corresponding author on request.

\section{Competing interests}

Yan Kestens holds shares in Polygon, a spin-off company that markets an online survey platform. It hosts Insight Forming (concept mapping application) used in the INTERACT project. eKogito was filed as an invention at Aligo (www.aligo.ca) in 2013, through Université du Québec à Trois-Rivières.

\section{Funding}

All authors were supported by INTErventions, Research and Action in Cities Team (INTERACT) team grant funded by the Canadian Institutes of Health Research (CIHR) under award number IP2-1507071C for Environments and Health: Intersectoral Prevention Research. The content is solely the responsibility of the authors and does not necessarily represent the official views of the CIHR. MW was supported by a 
Michael Smith Foundation for Health Research Scholar Award. DF was supported by a Canadian Research Chair in Population Physical Activity. YK was supported by a CIHR Applied Public Health Chair in Urban Interventions and Population Health.

\section{Authors' contributions}

ZPS led analysis, visualization, and writing of manuscript, CLF contributed to investigation and analysis. MC contributed to conceptualization. DF and MW provided investigation and writing review. YK led conceptualization, investigation, and writing-review.

\section{Acknowledgements}

We would like to thank the research staff who made this work possible. Marina Najjar and Benoît Thierry. We would also like to thank trainee Ludmilla Pommier-Morel who contributed to the project. Finally, we would like to thank all participants who were involved in this work.

\section{Additional Material}

Additional material is available detailing specific items resulting from the concept mapping exercises and individual scores for each item. Please see Table A1: Community group items by cluster (file name: Table A1.doc) and Table A2: Stakeholder group items by cluster (file name: Table A2.doc)

\section{References}

1. Crowley K, Head BW. The enduring challenge of 'wicked problems': revisiting Rittel and Webber. Policy Sci [Internet]. 2017 Dec 1 [cited 2021 May 4];50(4):539-47. Available from: https://link.springer.com/article/10.1007/s11077-017-9302-4.

2. Rabin BA, Brownson RC, Haire-Joshu D, Kreuter MW, Weaver NL. A glossary for dissemination and implementation research in health. J Public Heal Manag Pract [Internet]. 2008 Mar [cited $2021 \mathrm{Jul}$ 3];14(2):117-23. Available from: https://pubmed.ncbi.nlm.nih.gov/18287916/.

3. Northridge ME, Sclar ED, Biswas P. Sorting Out the Connections Between the Built Environment and Health: A Conceptual Framework for Navigating Pathways and Planning Healthy Cities. Vol. 80. Journal of Urban Health: Bulletin of the New York Academy of Medicine; 2003.

4. Griffiths J, Rao M. ., BMJ (Online. Public health benefits of strategies to reduce greenhouse gas emissions. Vol. 339: British Medical Journal Publishing Group; 2009. p. 1211.

5. Goodman N, Zwick A, Spicer Z, Carlsen N. Public engagement in smart city development: Lessons from communities in Canada's Smart City Challenge. Can Geogr [Internet]. 2020 Sep 1 [cited 2021 May 6];64(3):416-32. Available from: https://onlinelibrary.wiley.com/doi/full/10.1111/cag.12607. 
6. Wamsler C, Alkan-Olsson J, Björn H, Falck H, Hanson H, Oskarsson T, et al. Beyond participation: when citizen engagement leads to undesirable outcomes for nature-based solutions and climate change adaptation. Clim Change [Internet]. 2020 Jan 1 [cited 2021 May 6];158(2):235-54. Available from: https://doi.org/10.1007/s10584-019-02557-9.

7. Gaventa J, Representation, Community Leadership and Participation: Citizen Involvement in Neighbourhood Renewal and Local Governance. 2004.

8. Politis CE, Mowat DL, Keen D. Pathways to policy: Lessons learned in multisectoral collaboration for physical activity and built environment policy development from the Coalitions Linking Action and Science for Prevention (CLASP) initiative. Can J Public Heal [Internet]. 2017 Mar 1 [cited 2020 Nov 27];108(2):e192-8. Available from: https://link.springer.com/article/10.17269/CJPH.108.5758.

9. Firth CL, Stephens ZP, Cantinotti M, Fuller D, Kestens Y, Winters M. Successes and failures of built environment interventions: Using concept mapping to assess stakeholder perspectives in four Canadian cities. Soc Sci Med [Internet]. 2021 Jan 1 [cited 2020 Oct 1];268:113383. Available from: https://linkinghub.elsevier.com/retrieve/pii/S027795362030602X.

10. Fazli GS, Creatore MI, Matheson FI, Guilcher S, Kaufman-Shriqui V, Manson H, et al. Identifying mechanisms for facilitating knowledge to action strategies targeting the built environment. BMC Public Health [Internet]. 2017 Jan 3 [cited 2020 Mar 9];17(1):1-9. Available from: http://bmcpublichealth.biomedcentral.com/articles/10.1186/s12889-016-3954-4.

11. Kumar A, Lodha D, Mahalingam A, Prasad V, Sahasranaman A. Using 'design thinking' to enhance urban re-development: a case study from India. Eng Proj Organ J [Internet]. 2016 Oct [cited 2021 May 4];6(2-4):155-65. Available from: https://www.tandfonline.com/doi/abs/10.1080/21573727.2016.1155445.

12. Green $A E$, Aarons $G A$. A comparison of policy and direct practice stakeholder perceptions of factors affecting evidence-based practice implementation using concept mapping. Implement Sci [Internet]. 2011 Sep 7 [cited 2021 May 6];6(1):1-12. Available from: http://www.implementationscience.com/content/6/1/104.

13. Lobb R, Pinto AD, Lofters A. Using concept mapping in the knowledge-to-action process to compare stakeholder opinions on barriers to use of cancer screening among South Asians. Implement Sci [Internet]. 2013 Mar 23 [cited 2021 May 4];8(1):37. Available from: http://implementationscience.biomedcentral.com/articles/10.1186/1748-5908-8-37.

14. Stankov I, Howard NJ, Daniel M, Cargo M. Policy, research and residents' perspectives on built environments implicated in heart disease: A concept mapping approach. Int J Environ Res Public Health [Internet]. 2017 Feb 9 [cited 2021 May 6];14(2):170. Available from: .

15. Trochim WMK. An introduction to concept mapping for planning and evaluation. Eval Program Plann [Internet]. 1989 Jan 1 [cited 2018 Apr 25];12(1):1-16. Available from: https://www.sciencedirect.com/science/article/pii/0149718989900165.

16. Mehdipanah R, Malmusi D, Muntaner C, Borrell C. An evaluation of an urban renewal program and its effects on neighborhood resident's overall wellbeing using concept mapping. Heal Place. 2013 
Sep;1:23:9-17.

17. Hassmiller Lich $K$, Urban JB, Frerichs L, Dave G. Extending systems thinking in planning and evaluation using group concept mapping and system dynamics to tackle complex problems. Eval Program Plann. 2017 Feb;1:60:254-64.

18. Reis RS, Kelly CM, Parra DC, Barro M, Gome G, Malta D, et al. Developing a research agenda for promoting physical activity in Brazil through environmental and policy change. Rev Panam Salud Publica/Pan Am J Public Heal. 2012 Aug;32(2):93-100.

19. Kohl HW, Craig CL, Lambert EV, Inoue S, Alkandari JR, Leetongin G, et al. The pandemic of physical inactivity: Global action for public health. Vol. 380: The Lancet. Lancet Publishing Group; 2012. pp. 294-305.

20. Vaughn LM, Jones JR, Booth E, Burke JG. Concept mapping methodology and community-engaged research: A perfect pairing. Eval Program Plann. 2017 Feb;1:60:229-37.

21. Allen ML, Schaleben-Boateng D, Davey CS, Hang M, Pergament S. Concept mapping as an approach to facilitate participatory intervention building. Prog Community Heal Partnerships Res Educ Action [Internet]. 2015 Dec 1 [cited 2020 Dec 15];9(4):599-608. Available from: /pmc/articles/PMC5451901/?report = abstract.

22. Kestens $Y$, Winters M, Fuller D, Bell S, Berscheid J, Brondeel R, et al. INTERACT: A comprehensive approach to assess urban form interventions through natural experiments. BMC Public Health [Internet]. 2019 Dec 10 [cited 2019 Jan 14];19(1):51. Available from: https://bmcpublichealth.biomedcentral.com/articles/10.1186/s12889-018-6339-z.

23. Kane M, Trochim W. Concept Mapping for Planning and Evaluation. 2007.

24. Maechler M, Rousseeuw P, Struyf A, Hubert M, Hornik K, others. Cluster: cluster analysis basics and extensions. R Packag version. 2012;1(2):56.

25. Charrad M, Ghazzali N, Boiteau V, Niknafs A, Charrad MM. Package 'nbclust.'. J Stat Softw. 2014;61:1-36.

26. Oksanen J, Blanchet FG, Kindt R, Legendre P, Minchin PR, O'hara RB, et al. Package 'vegan.'. Community Ecol Packag version. 2013;2(9):1-295.

27. Rousseeuw PJ. Silhouettes. A graphical aid to the interpretation and validation of cluster analysis. $J$ Comput Appl Math. 1987 Nov 1;20(C):53-65.

28. Kruskal JB, Wish M. Multidimensional scaling. In: Sage University paper series on Quantitative Applications in the Social Sciences \#11. Beverly Hills: Sage; 1978. pp. 54-6.

29. Kaufman L, Rousseeuw PJ. Finding groups in data: an introduction to cluster analysis. 2005;342.

30. Godschalk DR. Land use planning challenges: Coping with conflicts in visions of sustainable development and livable communities. J Am Plan Assoc [Internet]. 2004 [cited 2021 Jul 3];70(1):513. Available from: https://www.tandfonline.com/doi/abs/10.1080/01944360408976334.

31. Ville de Montréal. Montréal Durable 2016-2020 «Succès et apprentissages» | Maison du developpement durable [Internet]. [cited 2021 Aug 27]. Available from: 
https://lamdd.org/actu/2021/montreal-durable-2016-2020-succes-apprentissages.

32. Nilsen P, Seing I, Ericsson C, Birken SA, Schildmeijer K. Characteristics of successful changes in health care organizations: an interview study with physicians, registered nurses and assistant nurses. BMC Heal Serv Res 2020201 [Internet]. 2020 Feb 27 [cited 2021 Aug 27];20(1):1-8. Available from: https://link.springer.com/articles/10.1186/s12913-020-4999-8.

33. Wiek A, Iwaniec D. Quality criteria for visions and visioning in sustainability science. Sustain Sci [Internet]. 2014 Oct 24 [cited 2021 Jul 3];9(4):497-512. Available from: https://link.springer.com/article/10.1007/s11625-013-0208-6.

\section{Figures}

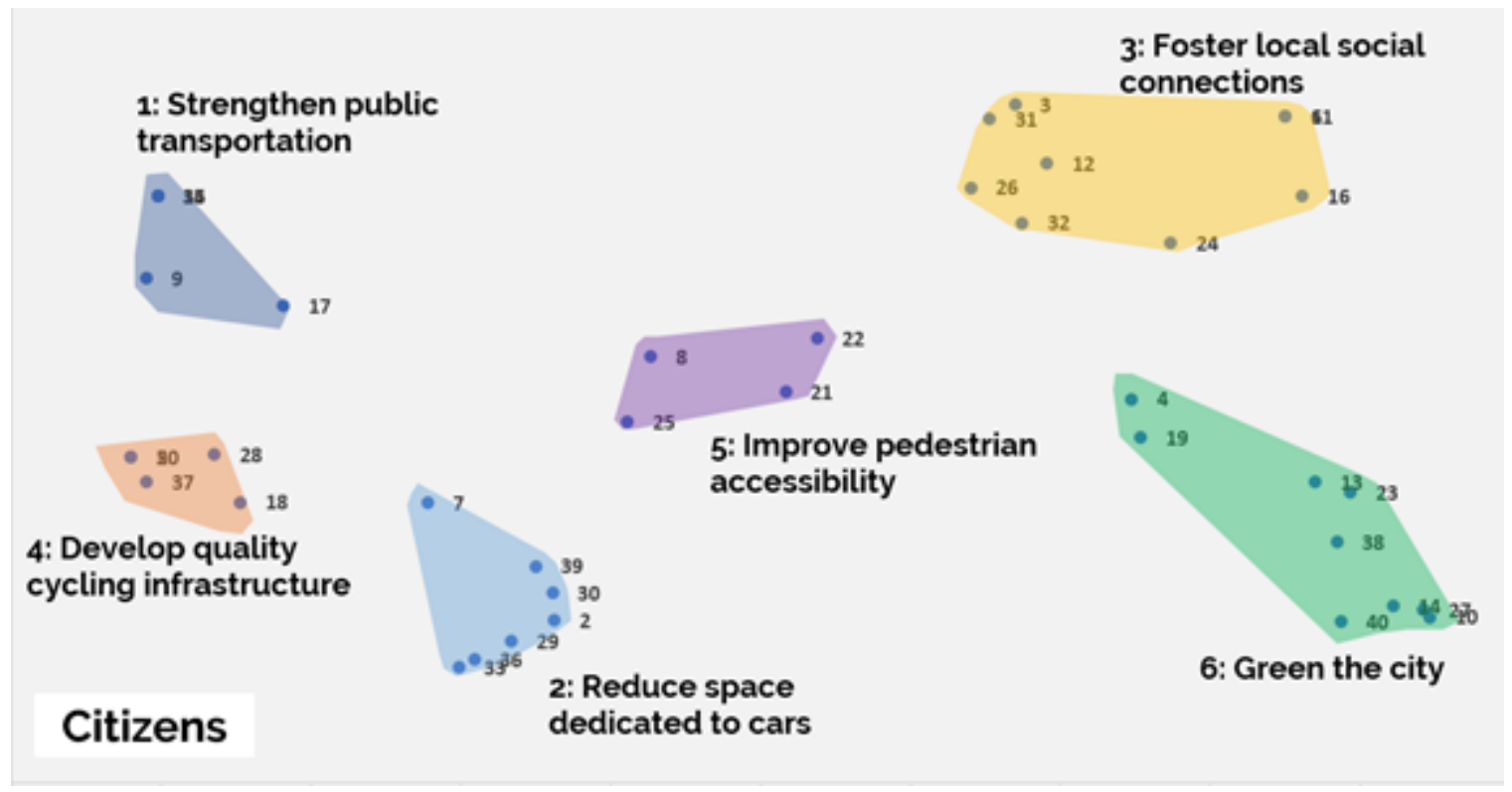

\section{Figure 1}

Concept map of community members' perception of interventions needed to improve quality of life in neighbourhoods 


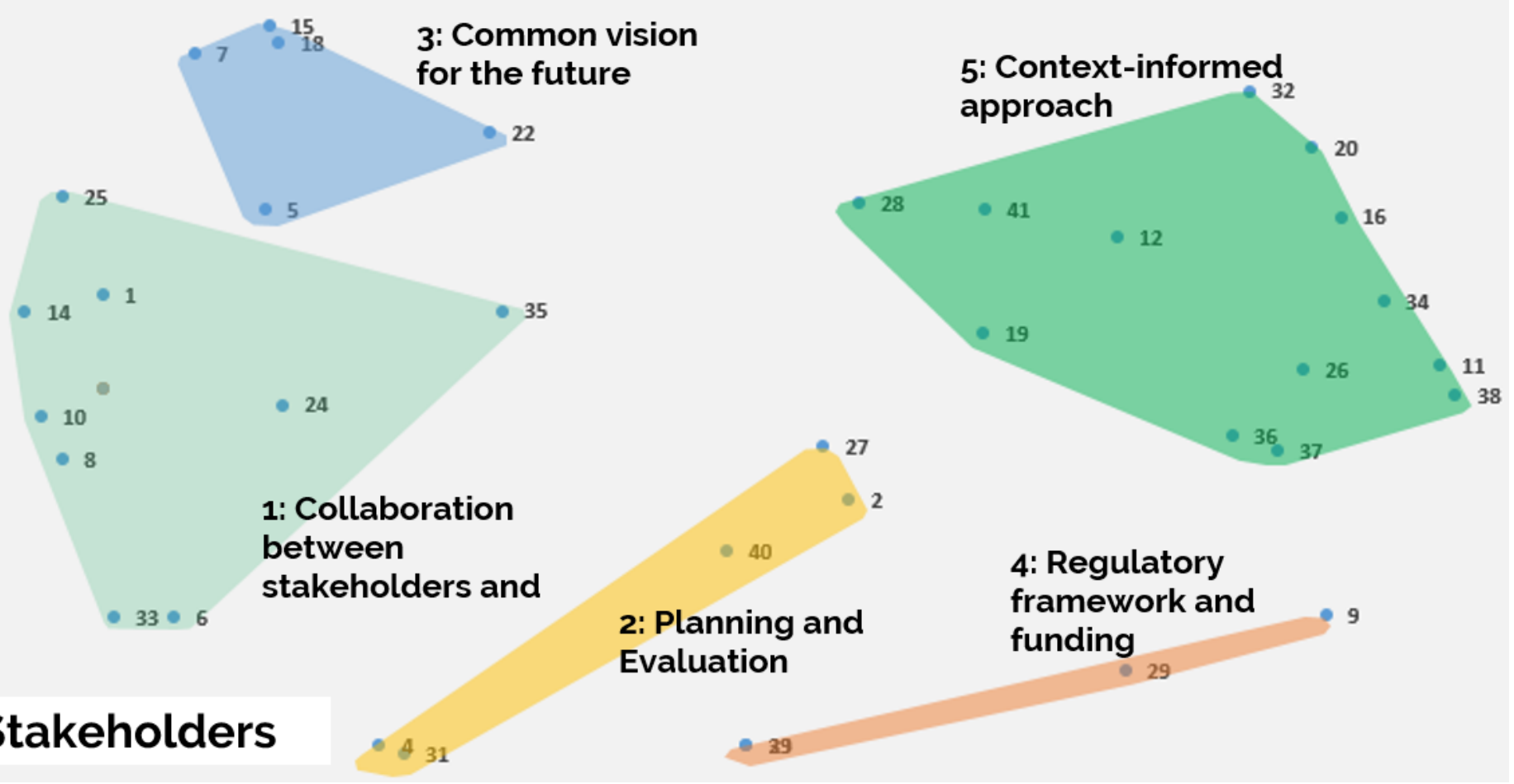

Figure 2

Concept map of stakeholder perceptions of success factors for built environment interventions

\begin{tabular}{|c|c|c|c|c|c|c|}
\hline & \multicolumn{5}{|c|}{ Stakeholders' perspectives on factors that contribute to successful interventions (how) } \\
\hline & & $\begin{array}{c}\text { Cluster 1: } \\
\text { Collaboration with } \\
\text { stakeholders \& } \\
\text { citizens }\end{array}$ & $\begin{array}{l}\text { Cluster 2: Planning } \\
\text { \& evaluation }\end{array}$ & $\begin{array}{l}\text { Cluster } 3 \text { : Common } \\
\text { vision for the } \\
\text { future }\end{array}$ & $\begin{array}{c}\text { Cluster } 4: \\
\text { Regulatory } \\
\text { framework \& } \\
\text { funding }\end{array}$ & $\begin{array}{l}\text { Cluster 5: Context- } \\
\text { informed } \\
\text { approach }\end{array}$ \\
\hline \multirow{6}{*}{ 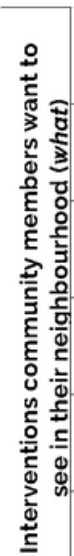 } & $\begin{array}{l}\text { Cluster 1: Strengthen } \\
\text { public transportation }\end{array}$ & & & & & \\
\hline & $\begin{array}{l}\text { Cluster 2: Reduce } \\
\text { space dedicated to } \\
\text { cars }\end{array}$ & & & & & \\
\hline & $\begin{array}{l}\text { Cluster } 3 \text { Foster local } \\
\text { social connections }\end{array}$ & & & & & \\
\hline & $\begin{array}{l}\text { Cluster 4: Develop } \\
\text { quality cycling } \\
\text { infrastructure }\end{array}$ & & & & & \\
\hline & $\begin{array}{l}\text { Cluster 5: Improve } \\
\text { pedestrian } \\
\text { accessibility }\end{array}$ & & & & & \\
\hline & $\begin{array}{l}\text { Cluster } 6 \text { : Green the } \\
\text { city }\end{array}$ & & & & & \\
\hline
\end{tabular}

Figure 3

Community $x$ Stakeholder Matrix combining community members' visions of desired neighbourhood change with stakeholders' understanding of factors that contribute to successful interventions 


\section{Supplementary Files}

This is a list of supplementary files associated with this preprint. Click to download.

- STROBEchecklistcompleted.docx

- TableA1.docx

- TableA2.docx 